\title{
ПСИХОЭМОЦИОНАЛЬНОЕ СОСТОЯНИЕ МЛАДШИХ ШКОЛЬНИКОВ С РАЗНЫМИ ТИПАМИ ПРИВЯЗАННОСТИ В ПЕРИОД АДАПТАЦИИ
}

\author{
Разина Н.В. (РГГУ, Москва, Россия) \\ natraz@inbox.ru

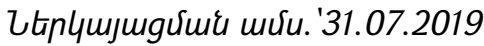

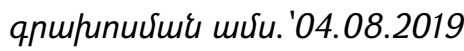

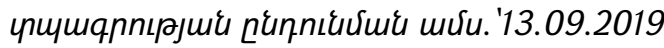

Статья посвящена изучению особенностей психоэмоционального состояния младшего школьника с разными типами привязанности к матери в период адаптации к первому классу. Результаты проведенного исследования показали, что эмоциональное состояние детей с разными типами привязанности качественно различается, у детей с ненадежной привязанностью значимо чаще встречается эмоциональная инверсия в познавательной сфере, чем у надежно привязанных детей. Также были выявлены значимые корреляционные связи между показателями надежности привязанности и общим фоном настроения младшего школьника, в процессе адаптационного периода к школе. Повторный срез лонгитюдного исследования показал, что у детей с низкими показателями надежности привязанности общее эмоциональное состояние улучшилось, а у детей с высокими показателями, наоборот, стало хуже.

Ключевые слова: эмочиональная сфера, младший школьник, школьная адаптация, привязанность, типы привязанности.

Всестороннее изучение адаптационных процессов первоклассников и факторов, влияющих на их успешное протекание, представляет огромный практический интерес, так как направлено на помощь юным школьникам, родителям и учителям в проживании этого непростого периода.

Фокус на взаимосвязь успешности школьной адаптации с особенностями привязанности ребенка к матери, поставленный в данной работе, связан с возрастающим интересом к более детальному и пристальному изучению теории привязанности Дж. Боулби и его последователей, в связи с новыми данными отечественных и зарубежных исследователей привязанности (К. Бриш, Н.Л. Плешкова, Н.Н. Авдеева). Многочисленные эмпирические исследования, проведенные в рамках этой теории за рубежом, говорят о значимости привязанности на всех жизненных этапах человека [2,53]. В пространстве отечественной науки за последние 15 лет появились данные о взаимосвязи привязанности к матери и различных аспектов личностного развития младших школьников (Борисова И.В., Василенко М.А., Ершова Ю.С., Пупырева Е.В. и др.). Данная работа развивает эту тему, напрямую сосредотачиваясь на вопросе значимости привязанности к матери в процессе школьной адаптации первоклассника, который находит яркое отражение в психоэмоциональном состоянии ребенка. 
Основываясь на представлении о роли эмоций в структуре личности ребенка, эмоциональное состояние ребенка рассматривается как показатель его благополучия или неблагополучия в период школьной адаптации, а эмоциональное отношение к школе - как субъективная оценка ребенком собственного школьного комфорта или дискомфорта. В свою очередь, надежная привязанность дает ребенку чувство безопасности, способствует личностному развитию и успешной социализации, что непосредственно определяет способность адаптации к жизни в целом.

Имеющиеся на текущий момент данные теоретических и эмпирических отечественных и зарубежных исследований позволяют сделать теоретическое предположение о том, что привязанность к матери является одним из факторов школьной адаптации первоклассника. Несмотря на отсутствие данных, о взаимосвязи непосредственно школьной адаптации и привязанности к матери, широко изучены взаимосвязи привязанности и различных факторов, каждый из которых сам по себе влияет на успешность школьной адаптации: самооценка ребенка, его автономия, социализация и социальная компетентность, социальная адаптация, познавательная активность, поведение, успеваемость и интеллектуальное развитие, - для каждого из этих аспектов надежная привязанность к матери является доказано благополучным, протективным фрактором, а ненадёжная, соответственно, фактором негативного развития.

Обобщая теоретические данные, можно предположить, что психоэмоциональное состояние детей с разными типами привязанности к матери в период адаптации к первому классу качественно различается. В частности, что у детей с надежным типом привязанности к матери эмоциональное состояние в ходе школьной адаптации более благополучное (в сравнении с детьми с ненадежным типом привязанности). Для подтверждения данной гипотезы было проведено исследование.

Эмпирическое исследование проводилось на базе общеобразовательной московской школы, в нем приняли участие 28 учеников первых классов (15 мальчиков и 13 девочек).

Исследование проводилось в два этапа. Первый этап проводился в ранний адаптационный период (2018г.), в ходе которого дети привыкают к обучению в школе. На этом этапе были проведены четыре методики для диагностики эмоционального состояния детей, уровня школьной тревожности и особенностей эмоционального отношения к школе: тест «Домики» О.А. Ореховой, тест школьной тревожности А.М. Прихожан, методика «Лесенка» в модификации Т.Д. Марцинковской и методика «Кактус» М.А. Панфиловой. Также на первом этапе была проведена диагностика привязанности: по шкале К. Кернс и по методике Н. Каплан. Заполнение тестовых материалов проводилось в соответствии с указаниями и инструкциями по предъявлению методик испытуемым, с учетом возрастных особенностей младшего школьника. 
Второй этап исследования проводился в начале второго полугодия обучения в первом классе (2019г.), когда в норме адаптация к школе должна уже завершиться [5,39]. На этом этапе с детьми был повторно проведен тест «Домики» с целью выявления изменений в их эмоциональном состоянии и отношении к школе. Во втором этапе приняло участие 22 ребенка из 28 (11 девочек и 11 мальчиков).

На основе полученных данных был получен своего рода портрет ребенка младшего школьного возраста с надежной и ненадежной привязанностью к матери.

Оценка привязанность проводилась по двум методикам. Шкала К. Кернс измеряет привязанность количественно, по степени надежности; методика $\mathrm{H}$. Каплан дает качественный анализ, позволяя выявить типы привязанности: надежная, тревожно-амбивалентная, избегающая и дезорганизованная.

Данные, полученные по шкале К.Кернс:

- $78 \%$ (22 чел.) - индекс от 2,7 до 3,5, что соответствует промежуточной категории - условно надежная привязанность;

- $14 \%$ (4 чел.) - индекс менее 2,7, что по данной методике классифицируется как ненадежная привязанность;

- 7\% (2 чел.) - индекс более 3,5, что соответствует высоконадежной привязанности.

Данные, полученные по методике Н. Каплан:

- $53 \%$ (15 чел.) - надежный тип привязанности;

- $25 \%$ (7 чел.) - тревожно-амбивалентный тип привязанности;

- $18 \%$ (5 чел.) - избегающий тип привязанности;

- 3\% (1 чел.) - дезорганизованный тип привязанности.

Сравнительный анализ результатов каждого испытуемого по двум методикам показал, что в крайних позициях данные строго совпадают. Все испытуемые, имеющие по шкале Кернс ненадёжную привязанность, показывают ненадежный тип и по методике Каплан; а все испытуемые, имеющие высоконадежные баллы по шкале Кернс, показывают надёжную привязанность по Каплан. Но необходимо отметить тот факт, что в выборке присутствуют и противоречивые данные, когда низкие баллы по Кернс соответствуют надёжной привязанности по Каплан и наоборот, высокие баллы по Кернс - ненадёжной привязанности по Каплан.

Статистическая обработка шкалы Кернс в группах с надежной и ненадежной привязанностью на значимость различий, дала достоверные результаты (t-критерия Стьюдента для независимых выборок, $p<0,01)$. Данные методик, направленных на оценку адаптации, показали, что для детей, находящихся в состоянии преобладания отрицательных эмоций характерно состояние вегетативной усталости, низкая самооценка, высокий уровень агрессии и большое число эмоциональных инверсий.

Детям, находящимся в состоянии преобладания положительных эмоций свойственно состояние оптимальной работоспособности (далее показатель ВК), отсутствие эгоцентризма, хорошая диффреренциация эмоциональной сферы, отсутствие эмоциональных инверсий и неуверенность в себе. 
В результате исследования психоэмоционального состояния детей с разными типами привязанности к матери можно сформулировать следующие положения:

У детей с ненадежной привязанностью чаще встречается заниженная самооценка. Это соотносится с данными диссертационных работ, приводимых в первой главе нашего исследования, где взаимосвязь привязанности к матери и самооценки младших школьников экспериментально подтверждена на гораздо большей выборке [1], [4].

Среди ненадежно привязанных детей, чаще встречается высокий уровень агрессии. Возможно, агрессия - способ канализации общей тревожности ненадежно привязанных детей.

У ненадежно привязанных детей вообще не встречается высокой школьной тревожности. Заметим, что высокую школьную тревожность демонстрируют всего четыре испытуемых (14 \% выборки), из них трое имеют надежную привязанность. Таким образом, мы наблюдаем тенденцию: большинство детей, демонстрирующих школьную тревожность, имеют надежную привязанность к матери.

Для тревожно-амбивалентных характерна заниженная самооценка, высокий уровень агрессии, неуверенность в себе и практически отсутствие стремления к домашней защите.

У избегающих детей также высокий уровень агрессии, однако, преобладает нормальная самооценка, вообще нет случаев неуверенности в себе и преобладает стремление к домашней защите.

Можно предположить наличие различных психологических защит, сложившихся у разных типов ненадежной привязанности. У тревожно-амбивалентных детей, вероятно, высокая тревожность, непостоянство и отсутствие стабильности и непредсказуемости в отношениях порождает сомнение в своей значимости для матери, и как следствие, низкую самооценку и высокую неуверенность в себе, а агрессию - как компенсацию, попытку заявить о себе, “докричаться" до партнера по отношениям. Отсутствие стремления к домашней защите у тревожноамбивалентных детей на данном этапе можно объяснить развернутостью в социум, поиск более стабильной фигуры привязанности.

Схожие данные были получены в исследовании канадских ученых о коррелятах типа привязанности и проблемности поведения [7,69], результаты которого говорят о наибольшей дезадаптивности в социуме у тревожноамбивалентных детей, так как их негативные реакции больше направлены вовне, чем у избегающих детей. Избегающие демонстрируют социально более заторможенное, скомпенсированное поведение.

Проведенный статистический анализ выявил следующие значимые различия в показателях эмоциональной сферы детей с разными типами привязанности.

Во-первых, выявлена взаимосвязь показателя, характеризующего общее эмоциональное состояние испытуемого (далее СО) с данными шкалы Кернс. 
Данные СО были разделены на две группы: группу детей с преобладанием отрицательных эмоций (показатели СО 20 и выше) и группу детей с нормальным и положительным эмоциональным состоянием (показатели СО 19 и ниже). Сравнение средних значений шкалы Кернс в этих двух группах с помощью t-критерия Стьюдента показывает статистически значимые различия $(\mathrm{p}<0,01)$.

Таким образом, можно говорить о выявленной взаимосвязи низких показателей надежности привязанности с доминированием у ребенка общего фона плохого настроения и отрицательных переживаний.

Во-вторых, наличие инверсии в блоке познания встречается значимо чаще в группе ненадежно привязанных детей, чем в группе надежных. Наличие или отсутствие инверсии в блоке познания сравнивалось с группами надежной и ненадежной привязанности по методике Каплан с помощью Точного теста Фишера (различия значимы на уровне $p<0,05)$.

Также значимые различия были выявлены в сравнении наличия или отсутствия инверсии в блоке познания с данными шкалы Кернс. Здесь данные испытуемых были разделены на две группы по критерию наличия или отсутствия инверсии в блоке познания, и с помощью t-критерия Стьюдента сравнились значения шкалы Кернс в полученных двух группах. Различия значимы на уровне $p<0,01$. Полученные данные уверенно (сопоставление по обеим методикам диагностики привязанности совпадает) говорят о том, что у детей с ненадежной привязанностью значимо чаще встречается эмоциональная инверсия в познавательной сфрере. Результаты исследования психоэмоционального состояния детей с разными типами привязанности к матери на втором этапе и анализ динамики показал, что эмоциональное состояние и отношение к школе надежно привязанных детей ухудшилось, а ненадежно привязанных - улучшилось. Это подтверждает и статистический анализ данных. Показатели шкалы Кернс значимо различаются $(p<0,05)$ в группах детей, состояние которых улучшилось и состояние которых ухудшилось.

Сопоставление данных улучшения/ухудшения эмоционального состояния с данными методики Каплан такой закономерности не выявило, однако, это может быть связано с недостаточно большой выборкой. В изменении отношения к школе статистически значимой разницы между детьми с разными типами привязанности не выявлено. Эти данные опровергают нашу второстепенную гипотезу, что эмоциональное состояние детей с надежной привязанностью будет более благополучным, чем состояние детей с ненадежной привязанностью.

Можно предположить, что на первом этапе школьной адаптации, когда дети находились в состоянии стресса, вследствие которого активировалось поведение привязанности, дети с ненадежной привязанностью оказались в более сложном положении, испытывая негативные переживания как от фрустрированной ненадёжной привязанности, так и от новой социальной ситуации. Возможно, спустя четыре месяца обучения, когда адаптация завершилась, и запустились 
компенсаторные механизмы и механизмы совладания, их эмоциональное состояние улучшилось, что и нашло отражение в полученных нами данных. При этом эмоциональное состояние надежно привязанных детей, не отягощенных негативными эмоциональными переживаниями, связанными с привязанностью, отражает «чистую» динамику, вызванную новой социальной ситуацией.

Другим объяснением выявленного нами феномена может послужить исследование Е.В. Пупыревой о взаимосвязи типа привязанности и автономии (самостоятельности) ребенка [6]. В этом исследовании была обнаружена парадоксальная на первый взгляд взаимосвязь: чем выше надежность привязанности, тем ниже дети субъективно оценивали свою автономию, и наоборот. Ученые объясняют полученные данные тем, что в случае ненадёжной привязанности автономия носит преждевременный характер и является следствием отстраненной позиции по отношению к матери $[3,6]$. В нашем случае может быть схожее объяснение: дети с ненадежной привязанностью, будучи более отстраненными от матери, демонстрируют большую самостоятельность в школе, легче адаптируются, а возможно, даже обращаются в школьную среду в поисках надежного объекта привязанности (например, учитель), вследствие чего их эмоциональное состояние улучшается.

Высокую теоретическую и практическую значимость для дальнейшего изучения теории привязанности представляет выявленная взаимосвязь низких показателей ненадежности привязанности с доминированием у ребенка общего фона плохого настроения и отрицательных переживаний в период адаптации к школе, и высоких показателей надежности привязанности, соответственно - с преобладанием положительного эмоционального фона.

Кроме того, важным результатом исследования является вывод о том, что у детей с ненадежной привязанностью значимо чаще встречается эмоциональная инверсия в познавательной сфере, чем у надежно привязанных детей. Эта закономерность является яркой иллюстрацией теоретического положения теории привязанности о соотношении потребности в привязанности и познавательной потребности ребенка. Предполагается, что ненадежная привязанность, тормозящая развитие познавательной сфреры, может стать серьезным фрактором, отягощающим формирование учебной мотивации, и, как следствие, учебной деятельности, успешности школьной адаптации и дальнейшего обучения.

Повторные замеры адаптации школьников показали, что у тех детей, общее эмоциональное состояние которых улучшилось после первого полугодия обучения в первом классе, показатели надежности привязанности ниже, тем у тех, чье общее эмоциональное состояние ухудшилось. Полученные данные могут найти широкое применение: как теоретическая основа для дальнейших эмпирических исследований взаимосвязей привязанности и школьной адаптации, так и в практической работе по просвещению, профилактике и консультированию родителей и учителей первоклассников. 


\section{Литература}

1. Борисова И.А. Особенности самооценки младших школьников с разными типами эмоциональной привязанности к матери: дис. канд. психол. наук, МГУ им. М.В. Ломоносова, М., 2007.

2. Бриш, К.Х. Терапия нарушении привязанности: От теории к практике / Пер. с нем. - М.: Когито-Центр, 2014. - 316 с.

3. Бурменская Г.В. Мировосприятие детей с разными типами привязанности к матери. Вестник Московского университета. Серия 14. Психология. 2011, №2, стр. 21-35.

4. Василенко М.А. Привязанность ребенка к матери как фактор ранней социализации: дис. канд. психол. наук, ГОУ ВПО «Курский государственный медицинский университет Министерство здравоохранения и социального развития Российской Федерации», Курск, 2011.

5. Костяк Т.В. Психологическая адаптация первоклассников. - М.: Издательский центр «Академия», 2008. - 174 с

6. Пупырева Е.В. Эмоциональная привязанность к матери как фактор становления автономии личности в младшем школьном возрасте: дис. канд. психол. наук, МГУ им. М.В. Ломоносова, М., 2007

7. Ellen Moss Correlates of Attachment at School Age: Maternal Reported Stress, MotherChild Interaction, and Behavior Problems. - Child Development, Vol. 69, No. 5.

\section{EMOTIONAL STATE OF JUNIOR SCHOOLCHILDREN WITH DIFFERENT ATTACHMENT STYLES DURING ADAPTATION PERIOD}

Razina N.V. (RSUH, Moscow, Russia)

This article deals with studies of emotional state of junior schoolchildren with different attachment style to caregiver in the period of adaptation to the first grade. The studies showed that children with various attachment styles show different emotional state: emotional inversion in cognitive sphere is significantly more common among children with insecure attachment style than with secure attachment style. The significant correlation was traced between parameter of security in attachment and background emotional performance of junior schoolchildren during adaptation to the first grade. The repeated observation of longitudinal study, the tests showed that emotional state of children with low parameter of attachment style's security was improved while the emotional state of children with high parameter got worse.

Keywords: emotional sphere, adaptation to school, attachment, attachment style. 